\title{
Socio-Demographic Factors and Compliance To Diabetic Health Education Among Diabetic Patients In A Tertiary Institution In Cross River State, Nigeria
}

\author{
Regina Etita Ella, (FWACN) \\ Associate Professor (PhD, M Ed, BSc Nursing, CERT HPM, RNT, RN, RM) \\ Department of Nursing Science, \\ Faculty of Allied Medical Sciences, College of Medicine, \\ University of Calabar, Cross River State, Nigeria \\ Felicia. Ekwok Lukpata, (FWACN) \\ Lecturer 1(PhD, MSc, BNsc Nursing, PGDE, RN, RM) \\ Department of Nursing Science, \\ Faculty of Allied Medical Sciences, College of Medicine, \\ University of Calabar, Cross River State, Nigeria \\ Ndukaku C. Nwakwue \\ Lecturer 11(MSc Nursing, BSc Nursing, RN) \\ Department of Nursing Science, \\ Faculty of Allied Medical Sciences, College of Medicine, \\ University of Calabar, Cross River State, Nigeria \\ Emmanuel Olayi \\ Clinical Instructor (BNSc Nursing, RN) \\ Department of Nursing Science, \\ Faculty of Allied Medical Sciences, College of Medicine, \\ University of Calabar, Cross River State, Nigeria
}

\begin{abstract}
This study investigated the factors that affect compliance to diabetic health education among diabetic patients attending clinic in UCTH, Calabar. Three specific objectives were outlined out of which three null hypotheses evolved and tested. The study adopted the survey (descriptive) design in its approach. From the population of 191 patients that enrolled in the clinic, 119 purposively selected were involved in the study. A 26 item questionnaire constructed by the researcher was used in data collection. This was ascertained to be both valid and reliable. The data collected was analyzed using simple percentages, one-way ANOVA and independent $t$-test statistical tool. The level of significance was taken at 0.05 alpha level. Findings showed that the level of compliance of diabetic patients to diabetic health education is low $((46.2 \%)$; patients' age $(P>0.05$, $\left.F_{2} 116=3.08\right)$, sex $(P>0.05, d f=117$, critical $t=1.97)$ and educational attainment $(P>$ $0.05, F_{3}, 115=2.68$ ) do not have significant influence on diabetic patients' compliance to diabetic health education. While conclusion revolves around these findings, it was recommended among other things that nurses intensify their efforts in diabetic health education, evolve new strategies and seek to verify other factors that could hinder compliance.
\end{abstract}

Key words: Diabetes Mellitus, Socio -demographic factors, Compliance, health education 


\section{BACKGROUND}

Diabetes mellitus (DM) is a chronic debilitating disease characterised by hyperglycaemia with disturbances of carbohydrate, fat and protein metabolism, resulting from defects in insulin secretion, action or both, that accounts for significant morbidity and mortality the world over [20]. [7] estimates that globally, 415 million adults are suffering from diabetes ( 1 in 11 adults) and this figure is projected to rise to around 642 million by 2040 [15]. Nigeria reportedly has Africa's highest burden of diabetes [13]. [15] asserts that [6] estimates that 1.6 million (1 in 53) Nigerian adults have diabetes while $60.7 \%(949,900)$ of Nigerian adults with diabetes are undiagnosed. In Cross River State, [4] reported the prevalence of diabetes mellitus to be 6.9\% in the southern senatorial district, and that this was much higher than internationally reported estimates for Nigeria. The researchers further disclosed that the prevalence of undiagnosed DM among residents of Calabar was also similar to studies elsewhere in Nigeria but much higher than the previous national prevalence survey, with close to a quarter of the adults having dysglycemia and 7\% having undiagnosed DM. These statistics are worrisome and constitutes a serious public health problem requiring the hands of all stakeholders, the health team and nurses in particular to be on deck. Nurses have to play their role, by continuous programme of health education to contribute to reduce the burden of this chronic debilitating disease on health care services. Intensifying the programme of health education by nurses, and patients' cooperation through compliance cannot be overemphasized.

In Nigeria, and in Cross River State studies have assessed knowledge of the causes, risk factors, complications, and management of diabetes mellitus among diabetics and non- diabetics and the effect of educational intervention on diabetes mellitus knowledge. While some results reported poor knowledge, others reported good or fair knowledge [8]. It is expedient that such knowledge should translate to effective compliance to diabetic health education among diabetic patients. The extent to which this is true is yet to be determined and the urgency to do this cannot be ruled out.

[17] and [21] definition of health Education has similarities. Health education is a profession of educating people about health. Areas within this profession encompass environmental health, physical health, social health, emotional health, intellectual health, and spiritual health. Health education for diabetic patients is primarily aimed at increasing the knowledge level of treatment regimens among diabetic patients and at empowering diabetic patients by also improving skills and confidence which will enable them to increasingly have control of their condition. Structured educational programmes as organized for self-management among diabetic patients are often multifaceted interventions providing information and also management skills around diet, exercise, weight, self-monitoring of blood glucose levels and medication use, management of hypo/hyperglycaemic episodes, diabetic skin care [9]. The impact of such education by nurses is to help in raising the level of compliance among diabetic patients.

Complying with health education is the best way to control diabetes and prevent its complications. Patient compliance or adherence is defined as the extent to which a person's behaviour coincides with health related advice [13]. Educating, motivating and guiding the patient to manage his/her diabetes can go a long way in lowering the burden of diabetes, on health care services. However, a study done at a primary care level in Egypt found that compliance of diabetic patients with most types of diabetes regimens was low [5]. Socio demographic factors like age, gender, educational level play important role in compliance to diabetes management. This study was therefore conducted to find the compliance of diabetic patients at UCTH regarding their exercise, diet, medication and follow-up. As a part of a larger study, we identified the personal characteristics which determined the compliance. Certain 
Ella, R. E., Lukpata, F. E., Nwakwue, N. C., \& Olayi, E. (2018). Socio-Demographic Factors and Compliance To Diabetic Health Education Among Diabetic Patients In A Tertiary Institution In Cross River State, Nigeria. Advances in Social Sciences Research Journal, 5(6) 82-92.

socio demographic factors identified in the literature review which tend to influence compliance of diabetic patients to health education were age, sex, level of education $[9,3,10]$

\section{Age and compliance}

Patients' age was identified as a factor that significantly influenced compliance to health education among diabetic patients in Saudi Arabia [3]. The study findings of [10,16,11, 1, and $3]$, revealed that young diabetic patients (age $<40)$ were more compliant with nearly all aspects of management of diabetes. Similarly [18] study on ocular findings in a diabetic retinopathy screening clinic in Southwest Nigeria, using 150 diabetic patients in Ekiti State University Teaching Hospital (EUTH), Ado Ekiti, showed that 124(82.7\%) respondents exhibited good level of compliance with diabetic health education while $26(17.3 \%)$ exhibited poor level of compliance. Out of the $82.7 \%$ that had good level of compliance, a correlation between their age and their compliance existed, which showed that compliance was more among the younger patients who were between 29-45years of age than those above 45years of age. However, [8] study revealed that compliance with health education was more among elderly patients. These patients were between 51-60 years of age. Further findings revealed that there was statistically no significant relationship between the age and compliance with health education.

\section{Gender and compliance}

In a systematic review on the clinical effectiveness of diabetes education models for type 2 diabetes, [9] reported a no correlation between the sex of diabetic patients and their compliance to health education. Despite the findings of no correlation, female diabetic patients complied with health education than the males. Gender was found to be a significant determinant of exercise compliance, with women being more compliant. This may be due to increased availability of time and less busy schedule for women which allows them to consider the various health advice. Furthermore, [16] study on Self-management in Diabetes Care: the Importance of Self-care Management Intervention in Chronically ill Patients Diagnosed with Diabetes showed that compliance to health education was mostly among female diabetic patients than the male diabetic patients. Similarly in Nigeria, [18], and Jasper et al. (2014), studies on compliance rates showed high level of compliance with health education among female patients. However the studies of [10] in British Columbia, to determine the efficacy of diabetes patient education and importance of self-management education in type 2 diabetes and that of [1] on effectiveness of health education program for type 2 diabetes mellitus patients attending Zagazig University Diabetes Clinic, Egypt (using 122 randomly selected type 2 diabetics attending diabetes outpatient clinic in Zagazig University, from January 2009 to April 2009), revealed that men exhibited high level of compliance. Further findings of Abdo and Mohammed showed that there was no significant relationship between the sex of diabetic patients and their compliance to health education

\section{Educational level and compliance}

Researchers such as [12,2, and 14] have examined diabetic patients' compliance to health education in different parts of Nigeria. [12] investigated factors for non-compliance to diabetic education among clients with diabetic mellitus in Maiduguri Teaching Hospital (UMTH) Borno State. The result showed that level of education hindered compliance to diabetic education. [2] study which examined diabetic education compliance among diabetic patients in Ilorin showed significant association $(\mathrm{P}<0.05)$ between patients with higher educational level and compliance. [14] investigated diabetes management regimens and effect of diabetes educational intervention on diabetics attending Nnamdi Azikiwe University Teaching Hospital (NAUTH). Diabetes educational intervention materials were developed and administered to 146 diabetic patients on 3 crucial areas of diabetic management viz: diet, exercise and drugs. There were positive lifestyle changes on the diabetics two years after the intervention. Diabetic 
knowledge significantly $((\mathrm{P}<0.05)$ improved from $59 \%$ to $63 \%$, which in turn improved on compliance.

As an effort to distort the course of diabetes which in recent time is noted to be increasing with its short term and long term complication, UCTH came up with diabetic clinic in 2013. The essence of the clinic is for health workers especially nurses to give diabetic patients expert management and care as well as proper health education. Despite this, the number of patients observed to return with diabetic-related complications and eventually admitted for care continues to be on the increase; this observation is suggestive of non or poor compliance of the patients to the diabetic health education. In the face of the above, many questions may be asked. Pertinent among such are the questions of; what factors could likely be responsible for the seemingly lack of compliance among patients? Attempt to provide answers to these questions and more has prompted this investigation. Compliance can go a long way in lowering the burden of diabetes, on health care services. Thus, the researcher sought to investigate the socio demographic factors influencing compliance to diabetic health education among diabetic patients attending diabetic clinic in UCTH, Calabar.

\section{Purpose of the study}

The study was designed to investigate the socio demographic factors influencing the compliance to diabetic health education among clients attending diabetic clinic in UCTH, Calabar.

Specifically the study sought to:

1. Determine the influence of age, on compliance to diabetic health education.

2. Ascertain the influence of sex, on compliance to diabetic health education

3. Determine the influence of educational level on compliance to diabetic health education

\section{Scope of study}

This study focused on the socio demographic factors that influence compliance to diabetic health education among diabetic clients attending diabetic clinic in UCTH, Calabar. It was covered male and female diabetic clients attending diabetic clinic in UCTH. The project covered the period of October, 2016 to February, 2017. The study investigated both Diabetes Mellitus (DM) type 1 and 2 while influencing factors examined were age, patients sex, and level of education.

\section{Significance of the study}

The result of this study would be useful to students, lecturers, health workers, educational planners and policy makers. Findings from this study would prompt educational curriculum planners to envision the need to incorporate a structured diabetes mellitus programme into the education curriculum of the various health professionals. Results would also serve as a guide in counselling and educating diabetic patients on the need to avoid the risk factors of diabetes mellitus in order to live a healthy life. Diabetic patients may benefit from this study as results from this research would enable them appreciate the need to assess their risk of developing the disease, motivate them to seek early and proper treatment and encourage them to adhere to health education advice/information given to them. Again, this study would serve as a reference point for further studies or research.

\section{Research hypotheses}

1. Patients' age does not significantly influence compliance to diabetic health education.

2. Patients' sex does not significantly influence compliance to diabetic health education. 
3. Patients' level of education does not significantly influence compliance to diabetic health education.

\section{Study design}

\section{MATERIAL AND METHODS}

Descriptive survey design which was institution based

\section{Research setting}

The setting for the study is Calabar Metropolis and the study site is University of Calabar Teaching Hospital (UCTH), Calabar. Calabar is the capital of Cross River State and constitudes two(2) LGAs: Calabar Municipality and Calabar South. As the first capital of Nigeria, Calabar remains an important city in the history of Nigeria. Located on a pennisula between Calabar River and the great Kwa River, Calabar lies between 4058 North of the equator and 8०17 East of the Greenwich Meridian with an estimated population of about 1.293million people (National Population Census, 2006). Main ocuupation is farming and Fishering. Major food consumption is carbohydrates,( garri, yams cocoayam, wateryam and plantainetc), protein( fish and crayfish) Vitamins and Fruits

\section{Study population}

The study population consisted of all diabetic patients registered with diabetic Clinic in UCTH, Calabar from October 2016 - February, 2017. This summed up to 191 patients from the hospital records. The accessible population was 119 diabetic patients from the diabetic Clinic in UCTH, Calabar. These were the diabetic patients, both male and female patients present at the Diabetic Clinic as at the time of distribution of questionnaire.

Only male and female patients who have been admitted before in the hospital for type 1 or type 2 diabetic case and have attended the outpatient clinic for up to three times were included in the study. Those who were attending the clinic for the first or second time and have never been admitted for diabetic management were excluded.

\section{Sample and sampling technique}

Purposive sampling technique was engaged to obtain 119 subjects, wherein all the subjects with the inherent characteristic under study (diabetic condition) were involved.

\section{Instrument for data collection}

A self-developed and structured questionnaire was used to elicit data from the respondents. The instrument was divided into three sections; Section A: Socio demographic features.

Section B: Compliance with health education. Positive comments by psychometric experts were suggestive for face validity. A measure of stability over time was assessed using a test -retest procedure which yielded a reliability coefficient of $0.78 \%$ after an interval of two weeks.

\section{Method of data collection}

The questionnaires were administered to the subjects through face-to-face administration with the help of a research assistant. The questionnaire was administered within working days. All copies of the questionnaire were administered and were retrieved on the spot after being correctly completed. 


\section{Data analysis}

The data collected were analyzed using descriptive and analytic statistics (percentages and frequencies, while the hypotheses were tested using one-way Anova and t-test via SPSS 18.0 at 0.05 level of significance).

\section{Ethical consideration}

An official permission was obtained from the institution, and then informed consent was obtained from the subjects who participated in the study. Patients were informed of the purpose of the study, confidentiality of the data and anonymity. Only those who gave informed consent were administered the questionnaire.

\section{General description of data/variables}

\section{RESULTS}

Table 1: Description of the respondents' personal characteristic.

Category per variable/

\begin{tabular}{|c|c|c|c|c|c|}
\hline \multirow{2}{*}{1.} & \multirow{2}{*}{$\begin{array}{l}\text { Personal variable } \\
\text { Age in years }\end{array}$} & \multicolumn{3}{|c|}{ number } & \multirow{2}{*}{$\begin{array}{l}\text { percentage } \\
21.01\end{array}$} \\
\hline & & 1. & Less than 18 yrs = & 25 & \\
\hline & & 2. & $18-39$ yrs $=$ & 46 & 38.66 \\
\hline & & 3. & 40 yrs and above $=$ & 48 & 40.34 \\
\hline \multirow[t]{2}{*}{2.} & Sex & 1. & Male $=$ & 61 & 51.26 \\
\hline & & 2. & Female $=$ & 58 & 48.74 \\
\hline \multirow[t]{5}{*}{3.} & Marital status & 1. & Married = & 53 & 44.5 \\
\hline & & 2. & Single $=$ & 29 & 24.4 \\
\hline & & 3. & Widow $=$ & 19 & 16.0 \\
\hline & & 4. & Divorced = & 10 & 8.4 \\
\hline & & 5. & Separated $=$ & 8 & 6.7 \\
\hline \multirow[t]{4}{*}{4.} & Religion & 1. & Christianity $=$ & 111 & 93.3 \\
\hline & & 2. & Islam $=$ & 4 & 3.4 \\
\hline & & 3. & Traditional $=$ & 3 & 2.5 \\
\hline & & 4. & Others $=$ & 1 & 0.8 \\
\hline \multirow[t]{4}{*}{5.} & Educational Qualification & 1. & No formal edu. $=$ & 20 & 16.81 \\
\hline & & 2. & Primary edu. = & 21 & 17.65 \\
\hline & & 3. & Secondary edu.= & 39 & 32.77 \\
\hline & & 4. & Tertiary edu. = & 39 & 32.77 \\
\hline
\end{tabular}

As shown in table 1, it can be deduced among other things that the burden of Diabetes is directly proportional to age of victims. In other words, incidence of diabetes rises or increases as individuals grow older. From a sample of 119 covered in this study, majority, (40.34\%) are aged 40 years and above. Other information as regards the personal variables indicates that the incidence of the disease is more on men (51.26\%) the married (44.5\%) and those of higher educational level (65.54\%). The implication of all is that, caution is necessary with respect to what one eats or does as he/she ages to check the possibility of going down with the disease, particularly if there are predisposing family trends of diabetes. The burden of marriage should be shared to relieve men and or both parties of some stressful factors that could predispose to diabetes. Further research may be required to ascertain the reasons for the high incidence of the disease among the highly educated as in this study (whom it is expected should know better) 


\section{Results for hypotheses}

Hypothesis 1: Patients' age does not significantly influence compliance to diabetic health education.

Table 2: Result of one-way ANOVA test of the influence of age of diabetic patients on their compliance to diabetic health education in UCTH, Calabar.

\begin{tabular}{lllll}
\hline Age category & $\mathrm{N}$ & $\mathrm{X}$ & $\mathrm{SD}$ & Std Error \\
\hline Less than 18 years & 25 & 2.68 & 0.557 & 0.111 \\
18-39 years & 46 & 2.91 & 0.725 & 0.107 \\
40 years \& above & 48 & 2.77 & 0.778 & 0.112 \\
Total & 119 & 2.81 & 0.716 & 0.066 \\
Source of variation & SS & df & MS & F-ratio \\
Between Groups 0.983 & & 2 & 0.492 & \\
& & & & \\
Within groups & 59.571 & 116 & & \\
Total & & 60.555 & 118 & \\
\hline P> $0.05, \mathrm{~F}_{2} 116=3.08$ & & & &
\end{tabular}

In Table 2, the calculated F-ratio is 0.957. This represents the observed influence of age of diabetic patients on their compliance to diabetic health education in UCTH, Calabar. As can be seen, the calculated F-value is less than the critical F-ratio of 3.08 at 0.05 level of significance with 2 and 116 degrees of freedom. On the basis of this, the null hypothesis is retained while the alternative hypothesis is rejected. The interpretation of this is that age of diabetic patient has no significant influence on their compliance to diabetic health education.

Hypothesis 2: Patients' sex does not significantly influence compliance to diabetic health education.

Table 3: Result of independent t-test analysis of the influence of sex of diabetic patients on compliance to diabetic health education.

\begin{tabular}{lllll}
\hline Patients' sex & $\mathrm{N}$ & $\mathrm{X}$ & $\mathrm{SD}$ & t-value \\
\hline Male patients & 61 & 2.87 & 0.718 & \\
Female patients & 58 & 2.74 & 0.715
\end{tabular}

$\mathrm{P}>0.05, \mathrm{df}=117$, critical $\mathrm{t}=1.97$.

As shown in 3 , the calculated t-value is 0.970 . This represents the observed difference in compliance to diabetic health education between diabetic male and female patients in the study area. As can be noted, the calculated t-value is less than the critical t-value of 1.97 at 0.05 level of significance with 117 degree of freedom. On the basis of this, the null hypothesis is retained while the alternate is rejected. The interpretation of this is that male and female diabetic patients do not differ significantly from each other in their compliance to diabetic health education. 
Hypothesis 3: Patients' level of education does not significantly influence compliance to diabetic health education. One-way ANOVA was used in carrying out the analysis as shown below

Table 4. Result of one-way ANOVA test of the influence of educational attainment on diabetic patients'

\begin{tabular}{lllll}
\hline Educational qualification $\mathrm{N}$ & $\mathrm{X}$ & SD & Std Error \\
\hline 1. No formal education & 20 & 2.75 & 0.639 & 0.143 \\
2. Primary education & 21 & 2.86 & 0.727 & 0.159 \\
3. Secondary education & 39 & 2.67 & 0.621 & 0.099 \\
4. Tertiary education & 39 & 2.95 & 0.826 & 0.132 \\
Total & 119 & 2.81 & 0.716 & 0.066 \\
\hline
\end{tabular}

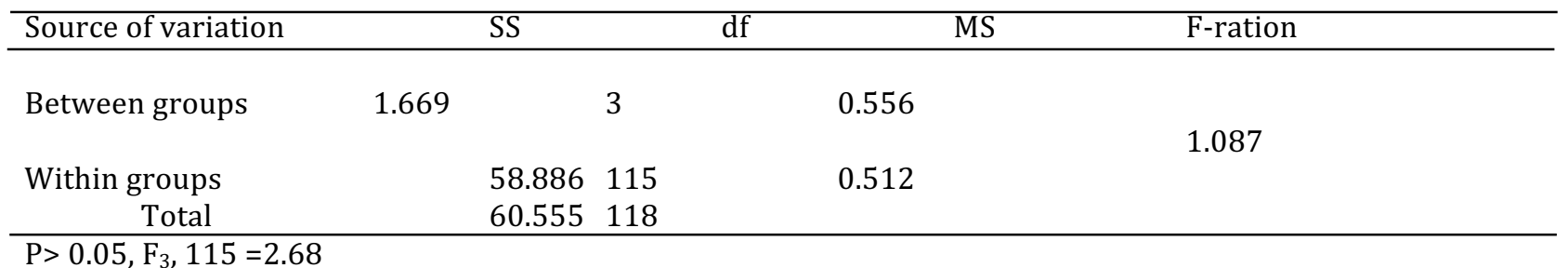

In Table 4, the calculated F-value is 1.087. This is less than the critical F-value of 2.68 with this result, the null hypothesis is retrained. This is interpreted to mean that there is no significant influence of patients' level of education on their compliance with diabetic health education in the study setting.

\section{DISCUSSION}

Compliance is the cornerstone of diabetes management. The level of compliance of diabetic patients to diabetic health education was low (46.2\%). This finding is similar to that of [5] whose study revealed a suboptimal compliance with all aspects, especially with diet and exercise.

The present study revealed that age has no significant influence on compliance to diabetic health education among diabetic victims. In other words, even though the disease burden increases with age, compliance to heath education does not flow in the same sequence. The implication of the result is that diabetic patients do not differ from one another in their levels of compliance to diabetic health education taking into consideration the variable of age. This first finding is contrary to that of $[9,10$, and 16] who reported from similar investigations that there is a correlation between the age of diabetic patients and their compliance to health education. They all reported that younger diabetic patients had good compliance than the older patients. From the above, it can be submitted that this finding is a deviation from earlier researchers. Given that earlier studies were all carried out in alien countries, it may be submitted that the current finding is peculiar to our (Nigerian) culture.

\section{Patients' sex and compliance to diabetic health education}

Further result showed that compliance to diabetic health education among patients is not sex dependent. Implying that there is no significant different in compliance between male and female patients, however, a close look at the mean scores of the two groups showed that male patients are better in this respect than the female $(2.87>2.74)$. This finding aligns with $[1,9$ and 18] who reported from similar investigations that there was no correlation between the sex of diabetic patients and their compliance to health education. The implication of this is that compliance or lack of compliance to health education is not dependent on the sex of the 
patient. On the contrary, [10] found that male patients comply to diabetic health education more than female patients whereas [8] submitted that female patients comply more than male patients..

\section{Level of education and compliance to diabetic health education among patients.}

The result also that there is no significant influence of educational qualification on patients' compliance to health education. The implication of this finding is that patients' response to compliance on health matters is not determined by the amount of education they have acquired.

Like the findings from the test of the first two hypotheses, this finding seems to deviate from general expectation, common experience; and the findings of researchers like [12, 2, 9, 10 and 18]. All of them noted educational attainment to be a significant factor in compliance to diabetic health education. In other words, one would expect that the higher the level of education one attains, the better and more appropriate his/her response to issues and matters as a result of more exposure/experience. Specifically, it was found among the researchers that patients with tertiary educational knowledge all have better and more favourable attitude towards diabetic health education compared to others with lower level of education. In the light of the current finding of increase incidence on the highly educated, and their compliance it calls for further action.

\section{CONCLUSION}

Firstly, it can be said that the compliance level of diabetic patients in UCTH, Calabar is not up to expectation and that factors responsible for such are varied. These can among others include distances such patients' homes and offices to the health facility, the attitude of health workers towards health education of the patients and the level of support and access to such support for diabetic health patients.

Also the observed poor compliance to diabetic health education observed among the patients is not majorly attributable to their personal variables such as age, sex, and level of education. The inter play of other factors listed above could play one role or the other. It can therefore be justifiably concluded that if such factors are addressed, the level of compliance of the patients towards diabetic health education will increase significantly.

The findings of this study reveal that the socio demographic variables in context do significantly influence diabetic patients' compliance to diabetic health education. Nurses in UCTH therefore need to be more patient friendly, maintain a good nurse patient rapport and maintain therapeutic communication to enhance compliance, while also seeking to investigate other factors

\section{Nurses should}

\section{RECOMMENDATIONS}

- Intensify efforts in diabetic health education, evolve new strategies and seek to verify other factors that could hinder compliance.

- Improve the understanding of these characteristics and to individualize the treatment regimen according to patients' requirements.

- Increase patients' awareness on diabetes mellitus and improve their understanding of their disease and compliance to advised treatment.

- Increase the amount of diabetic health education for patients. Possibly, take the language of instruction into consideration, to ensure that messages are rightly driven home. 


\section{Suggestion for further studies}

To keep research in this field of knowledge going, the researcher will make the following suggestions for further studies:

○ This study suffered some limitations such as lack of finance to do detailed survey, closer observation and home visits. A study in which provision will be made for such should be carried out. This will give room for more valid findings.

- A study with a larger scope may be covering all the local government areas in the state should be carried out. This will give room for generalization of results at least at the state levels if not geo-political or national.

- This study may be repeated in another setting, probably outside Cross River State. By so doing, provision can be made for comparison of cases and conditions across states or zone.

\section{References}

Abdo, N .M and Mohammed ME . (2010) Effectiveness of health education program for type 2 diabetes mellitus patients attending Zagazig University Diabetes clinic, Egypt. Journal of Egypt Public Health Assoc 85( 3-4): 113-30

Abdulazeez, I. F., Omole, M. And Ojulari, S. (2014), Medication compliance among diabetic patients in Ilorin, Nigeria. Journal of Dental and Medical Sciences, 13(3): 66-69

AbdulSalam, M and Saddiqui, A. F (2013) Socio-demographic Determinants of Compliance among Type 2 Diabetic Patients in Abha, Saudi Arabia. Journal of Clinical and Diagnostic Research, 7(12): 2810-2813. doi: 10.7860/JCDR/2013/6986.3708 PMCID: PMC3919358

Enang, O.E, Otu, E.EŁ,Essien O.E, Okpara H. I, Fasanmade, O.A, Ohwovoriole, A. E,and J Searle J (2014) Prevalence of dysglycemia in Calabar: a cross-sectional observational study among residents of Calabar, Nigeria. BMJ Open Diabetes Res Care 2(1): e000032.https://doi.org/10.1136/bmjdrc

Ibrahim, N R, Attia, S G, Sallam S A, Fetohy ,E M, El-Sewi F. (2012) Physicians' therapeutic practice and compliance of diabetic patients attending rural primary health care units in Alexandria. J Fam Community Med ,17:121-8.

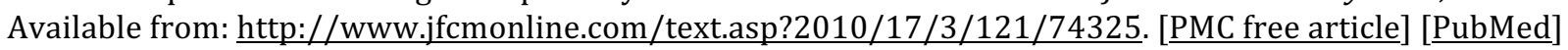

International Diabetes Federation (IDF Diabetes Atlas Fifth Edition, Middle East and North Africa-MENA), http://www.idf.org/diabetesatlas/5e/middle-east-and-north-africa..

International Diabetes Federation (IDF). IDF Diabetes Atlas. 7thed. 2015. http://www.idf.org/idf-diabetes- atlasseventh-edition Accessed 12th August 2017.

Jasper, U; Babatunde Ogundunmad G; Opara, C; Akinrolie, O; Pyiki, E, and Umar, A. (2014) Determinants of Diabetes Knowledge in a cohort of Nigeria Diabetics. Journal Diabettes and Metabolic Disorders, 13(39): 3- 4

Loveman, E, Frampton, G and Clegg, A J(2008) The clinical effectiveness of diabetic Education models for type 2 diabetes. A systematic review 12(9): 1-116

McGowan, P. (2011) The efficacy of diabetic patient education and self management Education in type 2 diabetes, Canadian Journal of Diabetes 35(1): 46-53.

Megeid G, and El-sayed, A. (2012) Health education intervention improves knowledge attitude and practices of mothers of insulin dependent diabetes mellitus in three (3) Primary Health Care Centers (PHCC) in Riyadh City, Kingdom of Saudi Arabia. Journal of Nursing Scholarship, 39(3): 243- 248

Mohammed, C; Jibri, U, and Dauda, S (2016) Noncompliance with treatment regimens Among clients with diabetic mellitus in University of Maiduguri Teaching Hospital North -Eastern Nigeria. Journal of Reaesarch in Nursing and Midwifery (JRNM) 5(1): 11-20

Murphy J, Coster G. (1997) “Issues in Patient Compliance” Drugs. 54(6):797-800. [PubMed]

Obidiozor, J. U (2012) Assessment of Diabetic Management regiments and effects of Diabetes educational intervention among diabetics attending Nnamdi Azikiwe University Teaching Hospital, Nnewi Anambra State, Nigeria. A Ph.D Dissertation in The department of Home Science, Nutrition and Diatetics, University of Nigeria, Nsukka. 
Otu, A.A, Akpan M, Effa, E, and Ennang O (2018) Prevalence of type 2 diabetes mellitus in Southern Cross River: a cross-sectional observational survey. International Journal of Diabetes in Developing Countries Bulletins' 09733930 DOI 10.1007/s13410-018-0606-5

Rosenbek, L. K. (2010) Self-management in Diabetes care: The importance of self Care management intervention in chronically ill patients diagnosed with diabetes. University of Southern Denmark, Odense Faculty of Health Sciences

The Joint Committee on Health Education and Promotion Terminology (JCHEPT, 2011),

Uloma, E (2014) Occular findings in a diabetic retinopathy screening clinic in South West Nigeria. Afr J Diabet Med 2011, 19: 15- 18

University of Calabar Teaching Hospital, Health records Department yearly reports, (2016)

World Health Organization (1999). Definition, diagnosis and classification of diabetes mellitus and its complications: report of WHO consultation. (WHO/NCD/NCS/99.2). Part 1: Diagnosis and Classification of Diabetes Mellitus. Geneva

WHO (2013) Report on the significance of diabetic awareness. New York Convention. 